\title{
Dramatizing Learning, Performing Ourselves: Stories of Theatre-Based Evaluation in Vancouver's Downtown Eastside
}

\section{Christopher Cook, Carolyn Camman, Andrew Leyland, Suzie 0'Shea, and Angela Towle \\ UBC Learning Exchange, University of British Columbia}

\begin{abstract}
Voices UP!, a play developed and performed collectively with participants from Vancouver's Downtown Eastside, illustrates the use of theatre as an innovative evaluation method for data collection, analysis, and knowledge translation. This artful process can convey complex, experiential evaluation findings and create engaging opportunities for learning, while building relationships and skills among participants. In this article we describe the creation process utilized for this theatre-based evaluation project, as well as guiding principles and lessons learned for evaluators who may want to engage in similar theatre-based participatory work.
\end{abstract}

Keywords: arts-based evaluation, knowledge translation, participatory evaluation, research-based theatre

Résumé : Voices UP!, une pièce de théâtre communautaire créée et interprétée collectivement avec des participants du Downtown Eastside de Vancouver, illustre l'utilisation du théâtre comme méthode d'évaluation novatrice pour la collecte de données, l'analyse et l'application des connaissances. Ce processus artistique peut transmettre des résultats dévaluations complexes et expérientiels et créer des mécanismes d'apprentissage intéressants, tout en construisant des relations et des compétences entre les participants. Dans cet article, nous décrivons le processus de création employé pour ce projet d'évaluation fondé sur le théatre, ainsi que les principes directeurs et les leçons apprises pour les évaluateurs et évaluatrices qui souhaiteraient séngager dans un travail participatif similaire basé sur le théâtre.

Mots clé : évaluation fondée sur les arts, traduction des connaissances, évaluation participative, recherche basée sur le théâtre

\section{SETTING THE SCENE}

In 1999, the University of British Columbia (UBC) founded the Learning Exchange to foster engagement between the university and communities of Vancouver's 
Downtown Eastside (DTES) (Towle \& Leahy, 2016). The DTES is an inner-city area made up of a diverse set of overlapping neighbourhoods, rich in history and art, many of whose residents face multiple barriers-including homelessness, poverty, and gentrification, as well as negative public perceptions and stigma (City of Vancouver, 2014; Eagle Bear, 2016). To serve the needs of the DTES community, the Learning Exchange brings together local residents, university students, and faculty members with a range of programming rooted in asset-based community development (Towle \& Leahy, 2016), knowledge sharing, and skill buildingprograms such as the Learning Lab.

Experimental from the beginning, the Learning Lab was created in 2013 as a low-barrier "middle space" between more formal learning opportunities, such as structured English conversation classes, and a drop-in style environment. Its aim is to motivate community members to try new things, build relationships, and explore leadership roles. Ideas for Learning Lab activities were gathered directly from the community, and took the form of ongoing clubs-such as chess, Mahjong, and math clubs-as well as diverse workshops, from robotics to button-blanket making. Reflecting a strengths-based approach, the Learning Lab aimed to create activities that could be self-sustaining, run by and for community members who were engaged as fellow learners and facilitators, with the support of Learning Exchange staff and university students. Learning Lab staff define leadership on a continuum, acknowledging that leading may look different for each community member, and encouraging learners and facilitators to discover what leadership means to them and to lead from where they are at.

We undertook an evaluation of the Learning Lab in 2015 to determine program outcomes and future directions. The objectives that required evaluation included to what extent the program (a) established a range of "middle space" educational activities that supported weekly participation by community members; (b) built new connections with external partners that supported diverse programming; and (c) developed activities cooperatively sustained and facilitated by local residents (Leyland, 2016). In accordance with the program's values, we sought evaluation methods that were participatory, creative, and fun and would support community engagement. In addition to a larger program evaluation that drew on a variety of more traditional quantitative and qualitative methods and a mixture of data sources, from semi-structured interviews to attendance sheets (Leyland, 2016), we initiated a theatre-based evaluation project. The Learning Exchange had previously explored ethnotheatre as a means of capturing program participants' voices (Balyasnikova, Higgins, \& Hume, 2017; Gillard \& Balyasnikova, 2015), and the Learning Lab had facilitated several collaborative art-making projects. Drawing on these experiences, and rooting the work in participatory evaluation approaches (Chouinard, 2013; Cousins \& Earl, 1992; Cousins \& Whitmore, 2007), we began creating a play called Voices UP!. Community members wrote and performed themselves in this play, side-by-side with staff, including the program evaluator, who co-created and appeared in the production. We selected theatrebased evaluation as an approach to allow community members to participate in a 
responsive, engaging evaluative process that centred on learning (Patton, 1994), while providing an accessible medium through which the evaluation narratives could be shared. Although the theatre-based project began as a component of the larger program evaluation of the Learning Lab (Leyland, 2016), it became an independent evaluation journey that lasted well-beyond the completion of the program evaluation (see Figure 1).

We describe the creation process utilized in the Learning Lab's theatre-based evaluation project, as well as guiding principles and "lessons learned" for evaluators who may want to engage in similar participatory work. In sharing our process, we offer a distinctive, creative map for engaging in collaborative arts-based evaluation with community members. A glossary of theatre terms is provided in the Appendix.

\section{WHY THEATRE? APPLICATIONS OF THEATRE IN EVALUATION AND RESEARCH}

There have been recent calls for the increased use of creative methods in evaluation (Searle \& Shulha, 2016; Simons \& McCormack, 2007), but-with the exception of Cozart, Gordon, Gunzenhauser, McKinney, and Petterson (2003) and Barone (1991) - the literature on the use of theatre in evaluation remains sparse. In other disciplines, research-based theatre is a methodology supported by substantial scholarship (Belliveau \& Lea, 2016), for example, in education (Beck, Belliveau, Lea, \& Wager, 2011; Belliveau, 2007; Donmoyer \& Yennie-Donmoyer, 1995; Norris, 2000; Prendergast \& Belliveau, 2018), and health (Gray, 2011; Hassall \& Balfour, 2016; Hodgins \& Boydell, 2013; Westwood \& Gordon, 2016). Drawing on the research-based theatre literature, we conceptualize theatre-based evaluation as an evaluation process rooted in the art of theatre.

A distinction should be made between arts-informed versus arts-based research (Cole \& Knowles, 2008), and, similarly, between arts-based and artsinformed evaluation practices (Searle \& Shulha, 2016). Whereas arts-informed research may use art as a component of a more traditional qualitative research design, for example, as a tool for data collection, arts-based work uses the chosen $\operatorname{artform}(\mathrm{s})$ to influence the entire research project. Research-based theatre encourages practitioners to consider how the various components of theatre might contribute to the inquiry process from start to finish. Although not all researchbased theatre projects are participatory, many utilize collective creation, an approach to theatre-making in which a group creates a play collaboratively (Boal, 1992; Kaufman, 2001; Norris, 2000; Okello, 2016). The script-creation process can serve to collect and analyze participant voices in a similar way to other narrativebased qualitative approaches (Saldaña, 2003). Transforming participants' words into a dramatic form allows the grouping and connection of similar themes and experiences. Additionally, theatre gives space for the inclusion of emotion and physical gesture in the data-collection and -analysis process. Dramatic techniques are particularly well suited for capturing and conveying complex data, with the 
ability to present multiple, even contradictory, narratives in coherent and engaging ways (Belliveau, 2006; Saldaña, 2003; Simons \& McCormack, 2007). Whether relying on simpler techniques, such as selecting and juxtaposing excerpts of verbatim quotations that are read aloud with minimal theatrical accoutrement, or through the application of more advanced approaches, such as creative stage direction, fictionalization, and metaphor (Rossiter et al., 2008), theatre has a powerful potential to communicate diverse experiences.

Theatre as a methodology may be of particular interest to evaluators working from a utilization-focused perspective, with an emphasis on maximizing the likelihood that findings will translate into actions by the intended users of the evaluation (Patton, 2008). Creating, performing, and witnessing live theatre can be an emotional experience that may evoke strong responses in both actors and audiences (Cozart et al., 2003; Rossiter et al., 2008; Westwood \& Gordon, 2016), conveying the emotional gravitas of participant experiences directly to stakeholders. Combined with theatre's immediacy and ephemeral nature, where a performance occurs as an interaction between actors and audience members in a particular moment in time, witnessing a play can powerfully motivate discussion, reflection, and action.

Other arguments for the use of theatre in evaluation include representing participant experiences more authentically and completely (Barone, 1991; Simons \& McCormack, 2007); making participating in, and learning from, an evaluation more accessible to a wider audience (Rossiter et al., 2008; Simons \& McCormack, 2007); and promoting ownership over findings by those whose experiences are being represented (Barone, 1991; Eakin \& Endicott, 2006). Such a collaborative, empowering approach is particularly appropriate in communities like the DTES, where participants may feel disenfranchised and experience marginalization.

\section{BEHIND THE SCENES: THE MAKING OF VOICES UP!}

Figure 1 illustrates the relationship between the theatre-based evaluation project and the larger, more traditional program evaluation. Voices UP! was created over 22 months, during which time participants met regularly to devise, rehearse, perform, and refine the script. Although the larger program evaluation ended in August 2016, the play continued as participants revised and performed new versions of the script until late 2017.

The collective creation process occurred within the predefined framework of the Learning Lab program evaluation: the staff and program evaluator decided that the play would focus on community members' experiences of taking part in Learning Lab activities. The Learning Lab was running several ongoing clubs and workshops at the time, and each was to have its own scene in the play. The staff also wanted the process to move through the general phases of theatre production: script creation, rehearsal, and performance.

Community participants in the play were drawn from individuals currently participating in Learning Lab activities and reflected the diversity of the DTES. 


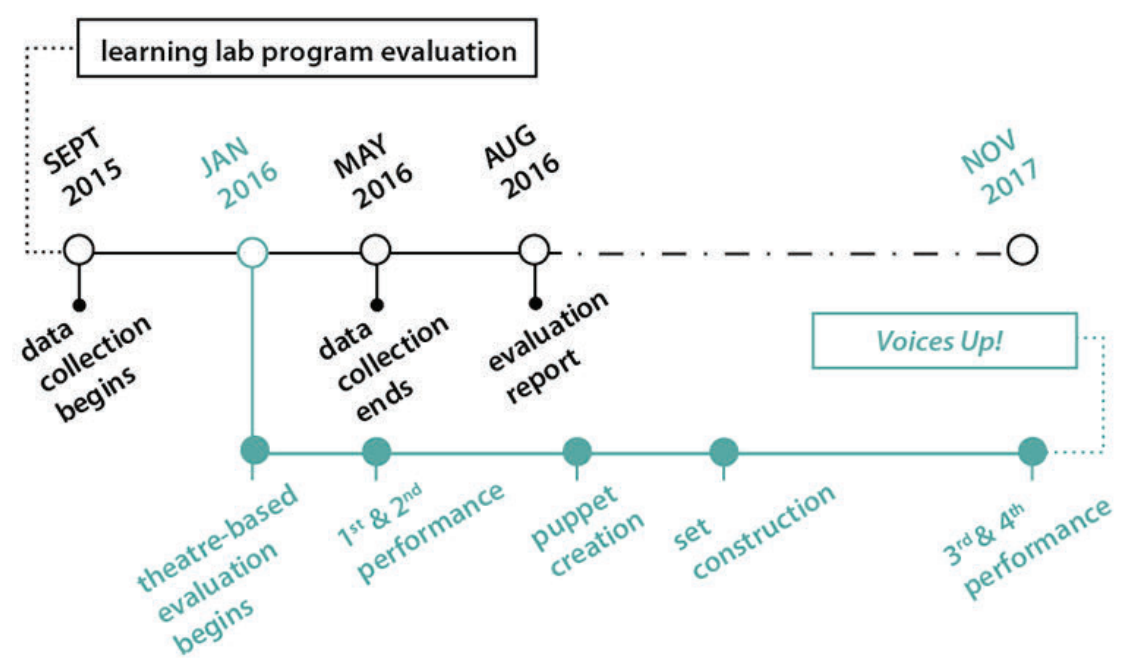

Figure 1. Evaluation timeline

The three staff-member participants were Suzie O'Shea (S.O.S.), who ran the Learning Lab program; Andrew Leyland (A.L.), the program evaluator; and Christopher Cook (C.C.), the Learning Lab assistant and a theatre artist. Learning Lab staff and community members all had previously established relationships. Like all Learning Lab offerings, Voices UP! was "drop-in" — care was taken to inform all potential participants that no registration or commitment was required and that they were free to drop in or out at any point during the theatre-based evaluation process. The process outlined here flows from scripting to rehearsal to performance, and movement through these phases was determined by the group. In other words, the group collectively decided when it was time to move from scripting to rehearsal, and if and when the script would be presented to an audience. The process was non-linear, as new lines were created mid-rehearsal, and scenes were rewritten throughout the process.

\section{Devising: Conversations to Dialogue}

Chatting over tea and snacks-that is how the data collection for this theatrebased evaluation began. Seven community members and three staff participated in the initial script creation. Participants from the Learning Lab's Mahjong Club, an introductory art workshop, and a community button-blanket making project were invited to take part in hour-long conversations about their experiences. Some participants had past performance experience, but for many Voices UP! was their first play. As part of these conversations, C.C. introduced participants to research-based theatre and collective creation.

To make these initial conversations welcoming for participants who may have been uncomfortable with recording, the meetings were not audio or video 
recorded. C.C. facilitated, asking questions such as "What was it like for you to take part in these activities?" and "What stands out to you when you think back on attending the workshop?" Based on notes of the responses, C.C. wrote the first draft of a scene and shared it with participants for revisions. Participants gathered weekly for one-hour meetings for the next eight weeks, conversing, writing, and revising the scenes. The resulting three scenes were framed by a collectively written prologue and epilogue, which knitted them together into a complete play. Participants were free to edit or withdraw their words from the script at any time and could choose whether they wanted to use a character name or their own name. Although attendance was not mandatory, absences were rare, and none of the participants dropped out of the script-creation process.

\section{Rehearsal: From Page to Stage}

All participants were given the option to perform their own words. Acknowledging that public speaking could present a barrier to participation, individuals could also record their dialogue for use during the performance or have another participant speak their words. Of the seven original community participants, five took part as live performers, one through audio recording and one by taking on the role of a director. An additional community member joined the cast as a voice actor, providing recorded monologues. All three staff members participated in the live performances.

As the collective brought the script "on its feet," staging the performers' movements, actions, and scene transitions, the script was considered fluid and was continually edited to reflect participants' perspectives. If a participant wanted to change a line from their own story, they were free to do so. If a participant wanted to add a new a line, the group came to a consensus by deciding whether the line fitted within the scope of the script (if it was related to their experience of the Learning Lab) and ensuring that other participants had the same opportunity to add dialogue. For example, when one participant wrote a line introducing themselves and describing their facilitator role at the Learning Exchange, all participants were given the option to add a similar line. Directing and staging decisions were facilitated by C.C. but were also made collectively. Rather than simply running through the script with participants reciting their lines, rehearsals were an extension of the devising process and took the shape of ongoing conversations.

\section{Lights Up: Evaluation Takes the Stage}

To create the most accessible performance situation possible, we presented Voices $U P$ ! as a stage-reading, with actors reading from scripts. For participants who found reading to be a barrier, fellow cast-members assisted with cuing and line recital.

Voices UP! was performed for the first time in May 2016, at a communityuniversity academic conference hosted by the Learning Exchange in Vancouver's DTES, to an audience of community members, researchers, and educators. The stage-reading was introduced to the audience by way of a pre-show speech, explaining the process used to create Voices UP! and preparing the audience for what 
they were about to see. The live performance was intercut with audio-recorded monologues, dialogues, and projections, representing other voices from the program evaluation. The 25-minute performance was followed by a facilitated question and answer period (talk-back) between audience and participants that lasted nearly 45 minutes.

\section{Encore Performances and Further Development}

Successive performances over the next 18 months offered participants the chance to develop the script further. The second performance, presented in the Learning Exchange drop-in space for community members, local organizations, and UBC staff and students, included an added scene about an additional Learning Lab club, performed by two new participants. The script continued to be revised and developed for a third performance, which saw the addition of sock puppets, driven by several participants who expressed an interest in creating puppets for the show. Prior to the third performance, participants also designed and constructed a set. The third and fourth performances were presented to audiences of professional evaluators, at the 2017 Canadian Evaluation Society (CES) Conference, and the CES BC and Yukon Chapter Annual General Meeting, respectively.

\section{Evaluation through Dramatization}

The central image of the play is captured in its title, Voices UP!, and refers to the stories and perspectives of everyone involved in the project. The performance used a wide range of dramatic techniques, including puppets, audience participation, stage directions, and sound design, to bring the Learning Lab experience to life in ways that would be difficult to achieve with a written report.

The Voice UP! script (2017) contains four distinct scene categories. The first category, Dramatizing Numbers, facilitated the inclusion of quantitative data gathered as part of the larger program evaluation and background material necessary for the audience's understanding. The following script selection, from the play's prologue, provides an example of this scene category and draws on data such as attendance and facilitator records.

\section{Prologue}

SUZIE and ANDREW enter and address the audience.

SUZIE: (to audience) Over 500 individual workshop sessions, club meetings, and learning opportunities-

ANDREW: (to audience) Reaching nearly 400 local participants-

SUZIE: Made possible by over 40 volunteer facilitators-

ANDREW: Over the past four years-

SUZIE: Five days a week-

BOTH: Around 800 days of programming.

ANDREW: All of this makes up the Learning Lab at the UBC Learning Exchange. 
SUZIE: My name's Suzie, I coordinate the Learning Lab. We support people to take a step outside their comfort zone, so we're standing at their learning edge together.

ANDREW: And I'm Andrew, I'm a UBC student, working at the Learning Exchange part-time, to evaluate the Learning Lab. It was a three-year pilot program-pretty experimental. And now it's been 3 years, so the question is: how'd we do?

BOTH: 500 workshop sessions, 400 participants, 40 facilitators.

ANDREW: The Learning Lab.

SUZIE: (to ANDREW) The Learning Lab is also ... much more than these numbers. It's the voices and stories of all the people who participate. To really understand the Learning Lab, you have to spend a day in the life with us. Ready, Andrew?

ANDREW: Let's go! (Voices UP! Collective, 2017)

The prologue also exemplifies performing self-these roles were written and performed by the staff members S.O.S and A.L., who portrayed themselves in the play and shared autobiographical stories. The prologue serves to invite audience members to explore "a day in the life" with the Learning Lab alongside A.L., and to witness both his journey as a program evaluator and the stories of the evaluation participants.

The second scene category, Dramatizing Words, drew on qualitative data collected as part of the larger program evaluation. For example, a monologue was created from notes that A.L. made after an informal interview with a member of the Mahjong Club. This community member was a part of the program evaluation but not a participant in the theatre-based evaluation project. Using these notes as a starting point, combined with the experiences of Voices UP! participants from the Mahjong Club, a composite character with the fictional name of Judy was created. Composite characters are drawn from the experiences of multiple individuals, encompassing more than one participant's story. Such characters offer privacy to individuals taking part in the project, allow for the grouping of similar experiences into a single character, and promote dramatization of the data. Not all data sets are inherently dramatic, and collected stories may need to be restoried into a new form to work as a monologue or dialogue on stage. Research-based theatre scholars have pointed to the tension between creating art and engaging in research, and to the pull for artistry to overtake the research (Belliveau, 2006; Saldaña, 1998, 2003). For theatre-based evaluators the same tension exists. Drama is the means by which the evaluation is being brought to life, not a licence for fictionalization. Nonetheless, some fiction, such as a composite character, has a place in theatre-based evaluation.

The third category of scene, Dramatizing Conversations, includes dialogue that was quoted from or inspired through conversations with participants during script devising and rehearsal. Participants engaged in these conversations after learning about collective creation, with the intention of creating lines that could 
be used in the play. For example, in the play's Epilogue, a character named Maria offers the feedback, "We want activities that help us make connections in the community, to use the skills we're learning to give back" (Voices UP! Collective, 2017).

The fourth category, Dramatizing Puppets, includes scenes created for the sock puppets. Both the third and fourth categories provided a means to go beyond the larger program evaluation, collecting and conveying a deeper understanding of participants' experiences, such as the emotional and relational connections captured by a fourth selection from the script-the puppet scene. Puppets appeared to offer participants freedom from censorship (Cook \& Belliveau, 2018). When devising the puppet scene, participants pulled on their sock puppets. Functioning like a mask, it was the puppets, not the participants, who were discussing the ups and downs of taking part in the Learning Lab. For example, the sock poppet Love says,

Don't underestimate relationship. We can talk-talk-talk-talk and it all comes back to one word: Relationship. ... How can you make the workshops and clubs ... more attractive? If you come up to me and say, not just- "Hey, this is happening now." But, "Hey, this is happening now and I'm going-do you want to come with me, do you want to come too?" (Voices UP! Collective, 2017)

\section{PLAYMAKING PROCESS: GUIDING PRINCIPLES}

Beyond traditional evaluation approaches, theatre-based evaluation offers a means of engaging and retaining participants, developing relationships, building capacity as both evaluators and theatre-makers, and stimulating in-depth discussions through performance. Theatre-based evaluation can also transform perspectives on evaluation. Rather than only an intellectual exercise, Voices UP! demonstrated that evaluation can be a creative, playful act, capable of emotionally involving participants and audiences through art-making.

We identify three core principles that guided our process:

(1) Creating collectively. Just as "capacity-building is inherent to participatory approaches" to evaluation (MacLellan-Wright, Patten, dela Cruz, \& Flaherty, 2007, p. 102), skill and knowledge sharing is intrinsic to collective creation. Group collaboration created a sense of shared ownership among participants and meant that no one person was required to be an expert at everything and everyone had a chance to lead. For example, while C.C. could assist with staging during rehearsals, he had no experience in set design or construction. Other participants led this process, teaching him and others how to saw and build a transportable stage set. The capacity building inherent in Voices UP! allowed participants to take part in an evaluation process in a creative manner, while also gaining transferable skills. 
(2) Staging ourselves. Staff worked alongside the participants, taking part in writing and performing, both as themselves and other characters. Embedding staff in the process allowed bonding and relationship building, as everyone shared the nervousness and excitement of each performance (Cook \& Belliveau, 2018). The process created a collective identity, symbolized by the Voices UP! T-shirts that all participants wore to performances. As Chouinard (2013, p. 245) writes about participatory evaluation, "learning takes place" through "the relationships that are created." Staff and community participants supported each other while performing self, embodying personal stories on stage. Research in counselling psychology has suggested that performing self is an empowering experience that can catalyze personal growth and learning (Westwood \& Gordon, 2016). In Voices UP!, performing self also ensured that selfreflexivity was present throughout the evaluation project (van Draanen, 2017), as participants devised and revised means of conveying their evolving experience to audiences over 22 months.

(3) We are all artists. One of the challenges of using theatre in research and evaluation contexts is overcoming participants' fears of being inadequate artists (Simons \& McCormack, 2007). Voices UP! took an approach of recognizing everyone's potential to contribute, regardless of experience or skill level in theatre. Fostering an environment where people felt welcome and comfortable, sometimes through something as simple as serving tea and apple slices during script-writing meetings and rehearsals, helped to make the prospect of engaging in artistic creation less intimidating. Allowing participants to choose their own roles and level of involvement supported community members and staff who were exploring theatre for the first time, while reflecting the Learning Lab's goal of providing low-barrier, strengths-based programming.

\section{CURTAIN CALL: FINDINGS AND LESSONS LEARNED}

Key findings of the larger Learning Lab program evaluation included the following: (a) sustainable activities grew from the patrons' interests; (b) activities focused on introductory art exploration were among the most popular; (c) activities that supported connections with external communities and organizations received positive responses from patrons as opportunities for them to give back. As illustrated by the excerpt from the Prologue, Voices UP! was able to communicate the numbers and findings captured in the final program-evaluation document to diverse audiences who otherwise may not have read the final report (Leyland, 2016).

The play also contributed new evaluation findings, through scenes such as the Epilogue, described above, and audience reaction. For example, during the second performance of the play, a Learning Exchange patron in the audience jumped up when A.L. spoke the line, "What did we forget [in our program evaluation]?," and 
shouted a request for more one-on-one music lessons. After the performance, the patron shared their story of taking part in previous one-on-one Learning Lab music lessons, and their experience of high facilitator turnover. These are two examples of how evaluation data was generated directly from the use of theatrebased evaluation (Leyland, 2016).

Several lessons learned emerged from the Voices UP! creation and performance process that may be useful for others engaging in theatre-based evaluation:

(1) Theatrical expertise. It was helpful to have at least one collective member with a theatre background to offer techniques, help draw out dramatic themes, and assist with writing and staging the performance. Groups interested in exploring theatre-based evaluation are advised to consult or collaborate with a theatre artist. For evaluators interested in learning more about collective approaches to theatrical exploration, see Norris (2000) and Johnstone (1987).

(2) Performances and talk-backs: a two-way street. Performances offered a "two-way" experience, with the presence of a live audience creating a new context for learning (Cozart et al., 2003). Including opportunities for interaction and discussion after performances through talk-backs took advantage of this learning context. Talk-backs allowed participants to step into the evaluator role, asking questions of the audience about their experiences of the play and conversing with individuals from diverse communities.

(3) Facilitating an ending. What would it be like if community members and staff were so excited by an evaluation process that they wanted to take part in it over and over again? During the summer of 2017, Learning Lab staff contemplated the legacy of the play once its performance run was over, while considering ways to create an empowering ending for those involved. After audience feedback at the third performance raised the idea of sharing the Voices UP! story in comic form, participants transitioned from collective play making to collective comic making. The cast created a comic book following the same collaborative process used to develop the play. Just as the character of Maria requests in the epilogue of Voices UP!, the comic creation process allowed participants to "use the skills" they learned "to give back" (Voices UP! Collective, 2017) and ensured that participants' commitment of time, skills, thoughts, and feelings was recognized and celebrated in a lasting, tangible form. The comic is freely available online (Camman et al., 2017) for evaluators and community members who wish to learn more about the theatre-based evaluation.

\section{EPILOGUE: FUTURE DIRECTION}

Voices UP! illustrates what theatre can offer evaluation practitioners beyond traditional evaluation approaches. Script creation allows for a creative, participatory 
means of data collection and analysis, one that has the potential to generate complex new insights through a broad range of theatre techniques, such as allowing participants to respond to questions using puppets. Performing a script created through theatre-based evaluation allows evaluators to share findings with diverse audiences in a more experiential, engaging way than a written report. As theatrebased evaluation allows participants to take leadership roles in both the evaluation process and the findings presentation, this participatory approach also creates an empowering learning experience.

This article shares one possibility for creating a theatre-based evaluation project, but any theatre paired with evaluation should be consistent with the program and context being evaluated. Voices UP! captured the stories of participants interested in taking part in a theatre project and is not meant to represent all voices from the Learning Exchange, or the DTES. Future research could explore the experiences of audience members who witness theatre-based evaluation projects (Belliveau \& Nichols, 2017) or examine changes fostered and action taken after theatre-based evaluation projects are conducted. Our theatre-creation process began with script writing, but movement or voice explorations are also possible starting points for theatrical creation. Future research could explore theatre-based evaluation projects that engage in diverse forms of the theatre-creation process.

Although Voices UP! was a drop-in activity, many community members participated in the production for over a year, and six took part for all 22 months. Voices UP! connected participants to the evaluation process, involving them beyond isolated activities (such as interview and focus groups) - they belonged to a play, and to a collective built on relationships. This process was equally engaging for audience members, as Voices UP! played to packed houses and people were often turned away at the door. For community-based organizations for which evaluation is key but may be difficult to do consistently, effectively, and meaningfully, the Voices UP! process offers an example of an innovative way of bringing evaluation narratives and findings to life.

\section{ACKNOWLEDGEMENTS}

The excerpts from Voices UP! were written and performed by Jay Jay, Ken Lee, Andrew Leyland, Suzie O'Shea, Super Sky, and Teresa Shu-Tak Wong, with Chris Cook. The authors wish to thank all the participants, students, and staff who took part in Voices UP! collective creation process over its two-year duration, as well as the UBC Learning Exchange.

This research-based theatre project took place on the traditional territory of the Musqueam, Squamish, and Tsleil-Waututh Nations.

\section{REFERENCES}

Balyasnikova, N., Higgins, S., \& Hume, M. (2017). Enhancing teaching English as an additional language through playfulness: Seniors (Ethno)Drama Club in Vancouver's Downtown Eastside. TESOL Journal, 9(3), 481-497. https://doi.org/10.1002/tesj.337 
Barone, T. (1991). Assessment as theater: Staging an exposition. Educational Leadership, 48(5), 57. Retrieved from http://www.ascd.com/ASCD/pdf/journals/ed_lead/ el_199102_barone.pdf

Beck, J. L., Belliveau, G., Lea, G. W., \& Wager, A. (2011). Delineating a spectrum of researchbased theatre. Qualitative Inquiry, 17(8), 687-700. https://doi.org/10.1177/1077800411 415498

Belliveau, G. (2006). Engaging in drama: Using arts-based research to explore a social justice project in teacher education. International Journal of Education \& the Arts, 7(5), 1-15. Retrieved from http://www.ijea.org/v7n5/

Belliveau, G. (2007). Dramatizing the data: An ethnodramatic exploration of a playbuilding process. Arts \& Learning Research Journal, 23(1), 31-51.

Belliveau, G., \& Lea, G. W. (Eds.). (2016). Research-based theatre: An artistic methodology. Bristol, England: Intellect.

Belliveau, G., \& Nichols, J. (2017). Audience responses to Contact!Unload: A Canadian research-based play about returning military veterans. Cogent Arts \& Humanities, 4(1). https://doi.org/10.1080/23311983.2017.1351704

Boal, A. (1992). Games for actors and non-actors. London, England: Routledge.

Camman, C., Cook, C., Jay, J., Lee, K., Leyland, A., O’Shea, S., . . \& \& Shu-Tak Wong, T. (2017, November 23). Voices UP! The comic. Retrieved from http://learningexchange. ubc.ca/2017/11/23/voices-up-the-comic/

Chouinard, J. A. (2013). The case for participatory evaluation in an era of accountability. American Journal of Evaluation, 34(2), 237-253. https://doi.org/10.1177/1098214013478142

City of Vancouver. (2014). Downtown eastside plan (Local Area Plan). Vancouver, BC: City of Vancouver. Retrieved from http://vancouver.ca/files/cov/downtown-eastside-plan.pdf

Cole, A., \& Knowles, J. (2008). Arts-informed research. In J. G. Knowles \& A. L. Cole (Eds.), Handbook of the arts in qualitative research: Perspectives, methodologies, examples, and issues (pp. 55-71). Thousand Oaks, CA: SAGE Publications. https://doi. org/10.4135/9781452226545

Cook, C., \& Belliveau, G. (2018). Community stories and growth through research-based theatre. LEARNing Landscapes, 11(2), 109-126. Retrieved from https://www.learning landscapes.ca/index.php/learnland/article/view/950

Cousins, J. B., \& Earl, L. M. (1992). The case for participatory evaluation. Educational Evaluation and Policy Analysis, 14(4), 397-418. https://doi.org/10.2307/1164283

Cousins, J. B., \& Whitmore, E. (2007). Framing participatory evaluation. New Directions for Evaluation, 1998(80), 5-23. https://doi.org/10.1002/ev.1114

Cozart, S. C., Gordon, J., Gunzenhauser, M. G., McKinney, M. B., \& Petterson, J. A. (2003). Disrupting dialogue: Envisioning performance ethnography for research and evaluation. Journal of Educational Foundations, 17(2), 53.

Donmoyer, R., \& Yennie-Donmoyer, J. (1995). Data as drama: Reflections on the use of readers theater as a mode of qualitative data display. Qualitative Inquiry, 1(4), 402-428. https://doi.org/10.1177/107780049500100403

Eagle Bear, D. (2016). Gentrification and change [Video series]. Vancouver, BC: UBC Learning Exchange, University of British Columbia. Retrieved from http://learningexchange.ubc.ca/campus/students/student-orientation-materials/ 
Eakin, J. M., \& Endicott, M. (2006). Knowledge translation through research-based theatre. Healthcare Policy, 2(2), 54-59. https://doi.org/10.12927/hcpol.2007.18528.

Gillard, S., \& Balyasnikova, N. (2015). Fear, courage, and joy: Three conversations at the Learning Exchange. Unpublished manuscript. Vancouver, BC: UBC Learning Exchange, University of British Columbia.

Gray, J. (2011). After the crash: A play about brain injury. Canadian Theatre Review, 146(1), 66-86. https://doi.org/10.1353/ctr.2011.0037

Hassall, L., \& Balfour, M. (2016). Transitioning home: Research-based theatre with returning servicemen and their families. In G. Belliveau \& G. W. Lea (Eds.), Research-based theatre: An artistic methodology (pp. 147-162). Bristol, England: Intellect.

Hodgins, M. J., \& Boydell, K. M. (2013). Interrogating ourselves: Reflections on arts-based health research. Forum: Qualitative Social Research, 15(1). http://doi.org/10.17169/ fqs-15.1.2018.

Johnstone, K. (1987). Impro. New York, NY: Routledge.

Kaufman, M. (2001). The Laramie project. New York, NY: Vintage Books.

Leyland, A. (2016). Learning Lab evaluation report [Unpublished report]. Vancouver, BC: UBC Learning Exchange, University of British Columbia.

MacLellan-Wright, M. F., Patten, S., dela Cruz, A. M., \& Flaherty, A. (2007). A participatory approach to the development of an evaluation framework: Process, pitfalls, and payoffs. Canadian Journal of Program Evaluation, 22(1), 99-124.

Norris, J. (2000). Drama as research: Realizing the potential of drama in education as a research methodology. Youth Theatre Journal, 14(1), 40-51. https://doi.org/10.1080/ 08929092.2000.10012516

Okello, B. F. (2016). The Ink Murderers can't hold it any longer. In G. Belliveau \& G. W. Lea (Eds.), Research-based theatre: An artistic methodology (pp. 27-42). Bristol, England: Intellect.

Patton, M. Q. (1994). Developmental evaluation. Evaluation Practice, 15(3), 311-319. https://doi.org/10.1016/0886-1633(94)90026-4

Patton, M. Q. (2008). Utilization-focused evaluation. Thousand Oaks, CA: Sage Publications.

Prendergast, M., \& Belliveau, G. (2018). Misperformance ethnography. In M. CahnmannTaylor \& R. Siegesmund (Eds.), Arts-based research in education: Foundations for practice (pp. 99-114). New York, NY: Routledge.

Rossiter, K., Kontos, P., Colantonio, A., Gilbert, J., Gray, J., \& Keightley, M. (2008). Staging data: Theatre as a tool for analysis and knowledge transfer in health research. Social Science \& Medicine, 66(1), 130-146. https://doi.org/10.1016/j.socscimed.2007.07.021.

Saldaña, J. (1998). Ethical issues in an ethnographic performance text: The "dramatic impact" of "juicy stuff." Research in Drama Education: The Journal of Applied Theatre and Performance, 3(2), 181-196. https://doi.org/10.1080/1356978980030205

Saldaña, J. (2003). Dramatizing data: A primer. Qualitative Inquiry, 9(2), 218-236. https:// doi.org/10.1177/1077800402250932

Searle, M., \& Shulha, L. (2016). Capturing the imagination: Arts-informed inquiry as a method in program evaluation. Canadian Journal of Program Evaluation, 31(1), 34-60. https://doi.org/10.3138/cjpe.258 
Simons, H., \& McCormack, B. (2007). Integrating arts-based inquiry in evaluation methodology: Opportunities and challenges. Qualitative Inquiry, 13(2), 292-311. https:// doi.org/10.1177/1077800406295622

Towle, A., \& Leahy, K. (2016). The Learning Exchange: A shared space for the University of British Columbia and Vancouver's Downtown Eastside communities. Metropolitan Universities, 27(3), 67-83. Retrieved from https://eric.ed.gov/?id=EJ1120575

van Draanen, J. (2017). Introducing reflexivity to evaluation practice: An indepth case study. American Journal of Evaluation, 38(3), 360-375. https://doi. org/10.1177/1098214016668401

Voices UP! Collective. (2017). Voices UP! [Unpublished manuscript]. Vancouver, BC: UBC Learning Exchange, University of British Columbia.

Westwood, M. J., \& Gordon, A. (2016). Solace in theatre after war: Facilitating therapeutic change through theatre performance. In G. Belliveau \& M. J. Westwood (Eds.), Soldiers performing self in CONTACT!UNLOAD: Innovations in theatre and counselling psychology (pp. 79-84). Vancouver, BC: UBC Faculty of Education.

\section{AUTHOR INFORMATION}

Christopher Cook worked at the UBC Learning Exchange as the Learning Lab assistant from 2015-2017. He recently completed his MA in counselling psychology at UBC and has worked as a theatre artist for the last ten years. He is passionate about exploring theatre as both a therapeutic, learning, and research tool. His previous playwriting credits include The Better Parts of Mourning (the frank theatre company), Strip (Staircase Theatre), Gerty: Live! In Concert! (BC Buds Festival), and Quick Bright Things (Persephone Theatre). Voices $U P$ ! offered Chris his first experience of collective creation.

Carolyn Camman is an evaluation specialist at the UBC Learning Exchange as well as an evaluation consultant working out of Vancouver, BC. Their involvement in Voices UP! came later in its process, first as an audience member who suggested turning the play into a comic book and later as an evaluator providing consultation support to that process, including conducting a literature review and helping prepare this article for publication.

Andrew Leyland is a graduate student in the School of Population and Public Health at UBC. His research involves intergenerational inequality and the policies that shape population health. He performed a program evaluation of the Learning Lab between 2015 and 2016. He is deeply grateful for the opportunity to undertake a community-based program evaluation at the UBC Learning Exchange, and to learn about theatre-based evaluation in the process. In his spare time, Andrew enjoys rock climbing and brewing beer.

Suzie O'Shea was the community animator at the UBC Learning Exchange from 20132018. She has a BA in Social Studies in Social Care, an MA in Youth and Community Studies, and was proud to be part of Voices UP! in her role as the coordinator of the Learning Lab program, exploring how arts-based approaches can build leadership and connections in an accessible way and significantly influence social change. Voices UP! was her acting debut, but Suzie has been found performing in contemporary line dancing, learning the ukulele, and trying her hand at sewing.

Angela Towle is the academic director of the UBC Learning Exchange. In this role she serves as the academic champion for the Learning Exchange, ensuring that it is linked 
effectively with UBC's academic mission. Angela is an associate professor in the Department of Medicine and senior scholar in the Centre for Health Education Scholarship in the Faculty of Medicine at UBC. She is also Co-Director of Patient \& Community Partnership for Education in the Office of UBC Health. Angela joined the Voices UP! team to facilitate the talk-back session after each performance. 


\section{APPENDIX: GLOSSARY OF THEATRE TERMS}

arts-based research: Any research project that roots its methodological approach in creative expression or specific art forms.

audience participation: Inviting the audience to actively take part in the performance, such as by asking for volunteers to join a scene.

blocking: Performers' movements on stage, including entrance and exits cues and any physical gestures.

collective creation: A theatre project created by a group of people working together. The creators often take on dual roles as writer-performers, presenting the work themselves.

in-vivo dialogue: Script dialogue quoted directly from participants' own words. performing self: Actors portraying themselves and telling their biographical stories onstage.

research-based theatre: A methodology in which theatre informs every aspect of the research project.

stage directions: In a script, the playwright's notes to the actors, directors, and other theatre artists regarding the set, lighting, sound, prop, costume, or projection design; character emotions, intentions, or blocking; intended audience experience; etc.

stage-reading: A performance in which actors are blocked, moving about the stage with their scripts in hand. Stage-readings may include design elements, such as sets and props. An alternative format is a script reading, in which actors read the script while seated or standing, and no design elements are present.

talk-back: Following the performance, a facilitated conversation between audience members and theatre-makers.

theatre-based evaluation: An evaluation project that draws on research-based theatre methodology to conduct an evaluation rooted in theatre creation. 